\title{
Detrimental role for CCAAT/enhancer binding protein $\delta$ in blood-borne brain infection
}

JanWillem Duitman ${ }^{1 *+}$, Mercedes Valls Serón ${ }^{2,3+}$, JooYeon Engelen-Lee ${ }^{2,3}$, Matthijs C. Brouwer ${ }^{2,3}$, C. Arnold Spek ${ }^{1+}$ and Diederik van de Beek ${ }^{2,3+}$

\begin{abstract}
Background: The most frequent pathogen that causes bacterial meningitis is the Gram-positive bacterium Streptococcus (S.) pneumoniae. CCAAT/enhancer binding protein $\delta$ is a transcription factor that has recently been hypothesized to play a detrimental role in outcome of meningitis caused by S. pneumoniae. Here, we studied the role of C/EBPS prior to the development of pneumococcal meningitis.
\end{abstract}

Methods: Wild-type and C/EBPS-deficient mice (C/EBP $\delta^{-1-}$ ) were intraveneously infected with S. pneumoniae and sacrificed after 24 or 48 h. cebp $\delta$ expression, bacterial loads, inflammatory response and pathology in the brain were assessed.

Results: S. pneumoniae induces cebp $\delta$ expression in the brain during blood-borne brain infection. In comparison to wild-type mice, C/EBP $\delta^{-1-}$ animals showed decreased bacterial loads in blood and brain $48 \mathrm{~h}$ after inoculation. In the blood compartment, the host inflammatory response was significantly lower upon infection in C/EBP ${ }^{-/-}$ mice as compared to wild-type mice.

Conclusion: C/EBP $\delta$ facilitates bacterial dissemination to the brain and enhances the immune response in the blood compartment. Our study suggests that C/EBP $\delta$ plays a detrimental role during the initial development of blood-borne brain infection.

Keywords: CAAT/enhancer-binding protein $\delta$, C/EBPS, Blood-borne brain infection, Streptococcus pneumoniae, Experimental meningitis

\section{Background}

The Gram positive bacterium Streptococcus (S.) pneumoniae is a common colonizer of the respiratory tract [1]. S. pneumoniae can however become invasive and may spread from the upper respiratory tract to other organs, leading to life-threathening infections such as pneumonia, sepsis, or meningitis [2]. Meningitis is a disease of the central nervous system characterized by inflammation of the protective membranes covering the brain and spinal cord [3]. S. pneumoniae is the most common

\footnotetext{
* Correspondence: j.w.duitman@amc.uva.nl

${ }^{\dagger}$ Equal contributors

${ }^{1}$ Center for Experimental and Molecular Medicine (CEMM) Academic Medical Center, University of Amsterdam, P.O. Box 22660, 1100DD Amsterdam, The Netherlands

Full list of author information is available at the end of the article
}

etiological agent of bacterial meningitis and causes $70 \%$ of cases [4-6]. Despite the availability of effective antibiotic treatments and vaccination programs $[7,8]$, bacterial meningitis still has a high mortality rate in adult patients and almost half of survivors suffer from neurological sequelae (e.g., learning, hearing, and memory impartment, seizures, and motor deficits) due to permanent brain damage [6,9-15]. Consequently, it is essential to improve existing therapies for meningitis through improving our understanding of the underlying pathophysiology.

CCAAT/enhancer binding protein (C/EBP) $\delta$ is a member of the C/EBP family of transcription factors that currently is composed of 6 different unique members $(\mathrm{C} /$ $\mathrm{EBP} \alpha, \mathrm{C} / \mathrm{EBP} \beta, \mathrm{C} / \mathrm{EBP} \delta, \mathrm{C} / \mathrm{EBP} \gamma, \mathrm{C} / \mathrm{EBP} \varepsilon$ and $\mathrm{C} / \mathrm{EBP} \zeta)$ $[16,17]$. C/EBP $\delta$ is generally accepted to act as a pro- 
inflammatory transcription factor, and was found to be essential in $\mathrm{Fc} \gamma$ receptor-mediated inflammatory cytokine and chemokine production. C/EBP $\delta$ deficient macrophages failed to induce a full tumour-necrosis factor (TNF)- $\alpha$, macrophage inflammatory protein (MIP)-2 and MIP- $1 \alpha$ response induced by IgG Immune complexes [18]. Moreover, low dose lipopolysaccharide (LPS) stimulation of macrophages induces C/EBP $\delta$ expression, leading to higher interleukin (IL)-6, Monocyte Chemoattractant Protein (MCP)-1 and endothelin-1 levels [19]. C/EBPS also potentiates IL-6 expression in macrophages upon high dose LPS stimulation [20]. Recently, C/EBPS was shown to play a pivotal role in the host response to grampositive $S$. pneumoniae infections including pneumonia and meningitis [21, 22]. During pneumococcal pneumonia, C/EBPS exaggerates bacterial dissemination and wildtype mice succumb earlier to the disease as compared to $\mathrm{C} / \mathrm{EBP}^{-/-}$mice whereas in pneumococcal meningitis increased C/EBP $\delta$ expression in the brain was associated with increased bacterial growth, dissemination and the inflammatory response.

Most in vivo models that study the pathophysiology of bacterial meningitis involve the direct injection of pneumococci into the brain of mice or rats [23] and therefore aim to study host-pathogen interactions once infection is established in the meninges. The aim of the current study was to investigate the role of $\mathrm{C} / \mathrm{EBP} \delta$ prior to the onset of meningitis. Since an important route of central neurvous system (CNS) infection by bacterial pathogens is via the blood stream, we challenged wildtype and $\mathrm{C} / \mathrm{EBP}^{-/-}$mice with $S$. pneumoniae through intravenous injections. We show that $S$. pneumoniae induces C/EBP $\delta$ expression in the brain in blood-borne brain infection. Moreover, $\mathrm{C} / \mathrm{EBP}^{-/-}$animals showed decreased bacterial loads in blood and brain $48 \mathrm{~h}$ after inoculation. The reduced bacterial dissemination in the brain did however not result in a lower inflammatory response or reduced histopathology in the brain of $\mathrm{C} / \mathrm{EBP}^{-/-}$mice. Thus, our study suggests that $\mathrm{C} / \mathrm{EBP} \delta^{-/-}$modifies bacterial dissemination in blood-borne brain infection.

\section{Methods}

\section{Animals}

$\mathrm{C} / \mathrm{EBP}^{-/-}$mice, generated as described previously [24], were backcrossed at least 10 times to a C57BL/6 background. Wild-type mice were purchased from Charles River (Maastricht, the Netherlands). 8- to 12-week-old male or female animals were maintained at the animal facility of the Academic Medical Center (University of Amsterdam) with free access to food and water. All animal experiments were approved by the Institutional Animal Care and Use Committee of the Academic Medical Center, University of Amsterdam.

\section{Sepsis infection model}

Wild-type and $\mathrm{C} / \mathrm{EBP}^{-/-}$mice $(n=30$ per group) were inoculated into the tail vein with $5 \times 10^{5} \mathrm{CFU}$ of $S$. pneumoniae serotype 3, American Type Culture Collection 65303 (in $200 \mu \mathrm{l}$ saline) as previously described $[25,26]$. Control animals $(n=6)$ received saline only. At $24 \mathrm{~h}$ and $48 \mathrm{~h}$ after inoculation, organs were collected and homogenised as described previously [27].

\section{Determination of cytokines and chemokines}

TNF- $\alpha$, IL-6, Interferon (IFN)- $\gamma$ and MCP-1 levels were determined using a cytometric bead array multiplex assay (BD Bioscience, San Jose, CA, USA) as described previously [27].

\section{Real-time PCR}

Total RNA was extracted from murine brain homogenates using TriPure reagent (Sigma-Aldrich, St-Louis, MO, USA). For complementary DNA (cDNA) synthesis, RNA was treated with RQ1 RNase-free DNase (Promega, Leiden, the Netherlands) and reverse transcribed with SuperScript II Reverse Transcriptase and random hexamers (Life Technologies, Bleiswijk, the Netherlands). The real-time polymerase chain reaction (RT-PCR) was performed on a Bio-Rad MyiQ Single-Color RT-PCR Detection System using the Bio-Rad iQ SYBR Green Supermix (Bio-Rad Laboratories, Hercules, CA, USA). The c/ebp $\delta$ and Non-POU-domain containing octamer binding protein (NoNo, housekeeping gene), primers were described previously [22]. The C/EBPS expression levels were normalized to the NoNo reference gene.

A negative control without the Reverse Transcriptase was also used.

\section{Statistical analysis}

All data are expressed as means \pm SEM. Differences between groups were analyzed by $t$-test and when necessary corrected for nonparametric values by MannWhitney $U$ test. Differences in bacteremic brains were analysed by Fisher's exact test. Correlation was analysed by correlation analysis. Analyses were performed using GraphPad Prism version 6.0 (GraphPad Software, San Diego, CA, USA) or R [28]. Statistically significant differences were considered with a $p$ value less than 0.05 .

\section{Results \\ C/EBPS expression is increased in brain during pneumococcal sepsis}

To determine C/EBP $\delta$ expression in the brain during sepsis caused by S. pneumoniae, we measured c/ebp $\delta$ mRNA levels in brain tissue from wild-type mice inoculated with $5 \times 10^{5}$ collony forming units (CFU). As shown in Fig. 1a, c/ebp $\delta$ mRNA levels were low in brain 

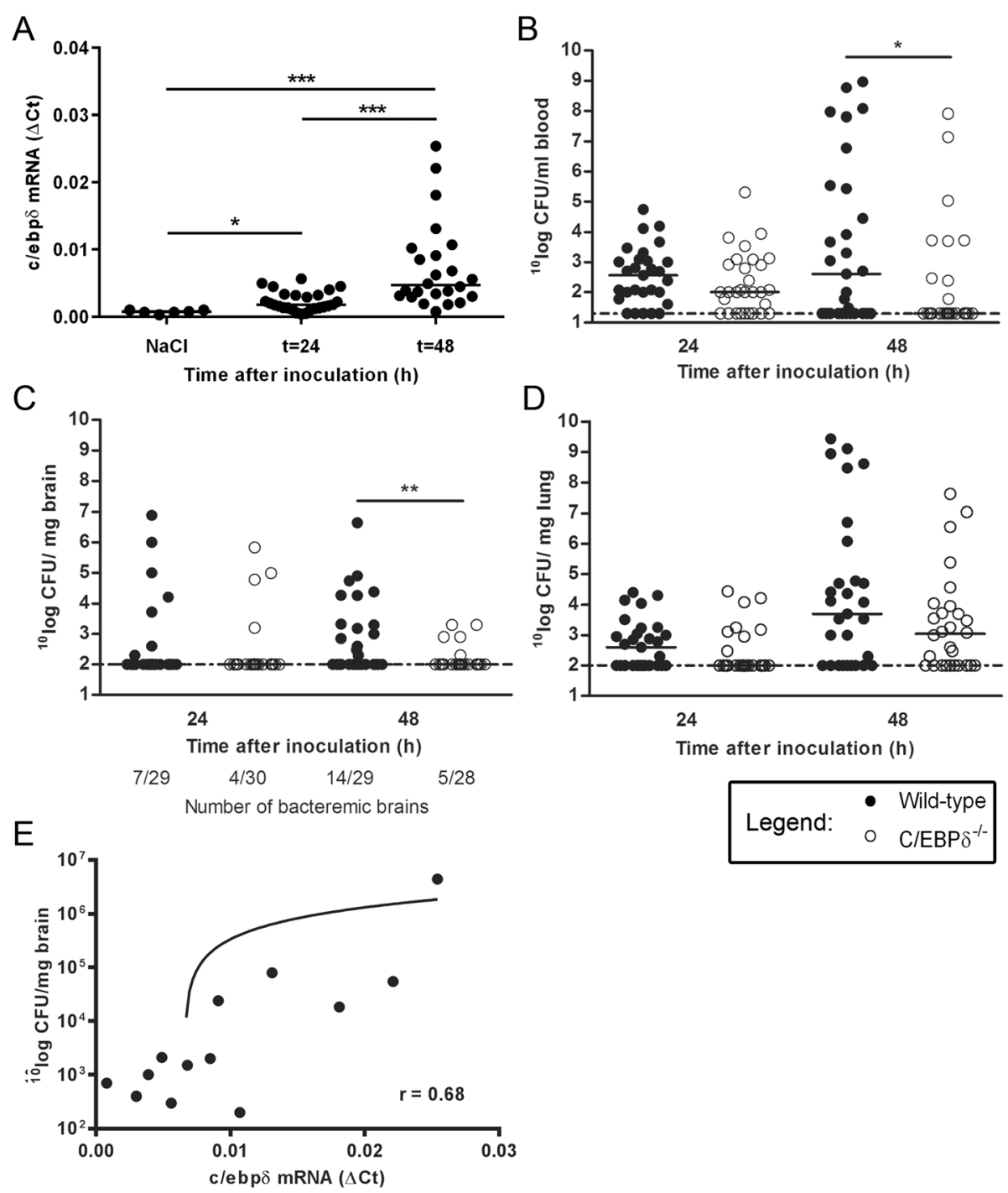

Fig. 1 C/EBP $\delta$ is detrimental for the blood-brain barrier upon intravenous pneumococcal infection. c/ebp $\delta$ mRNA (a) in wild-type brain tissue at different time points after intravenous inoculation with S. pneumoniae. Bacterial outgrowth in whole blood (b), brain (c) and lung (d) of wild-type and $\mathrm{C} / \mathrm{EBP}^{-1-} 24$ and $48 \mathrm{~h}$ after infection. Correlation analysis of cebpd mRNA expression and bacterial loads in the brain (e). Data are expressed as scatter dot plots with the median ( $n=6$ for controls; $n=30$ at both $\mathrm{t}=24$ and $\mathrm{t}=48 \mathrm{~h}$ post infection). ${ }^{*} P<0.05,{ }^{* *} P<0.01,{ }^{* * *} P<0.001$

of uninfected mice but significantly increased at $24 \mathrm{~h}$ (approximately 3-fold) and $48 \mathrm{~h}$ (approximately 10-fold) after S. pneumoniae inoculation.

\section{C/EBP $\delta$ aggravates bacterial dissemination from the blood to the brain}

In order to investigate the role of C/EBPS in the development of meningitis upon pneumococcal sepsis, wild-type and $\mathrm{C} / \mathrm{EBP}^{-1-}$ mice were intravenously inoculated with $S$. pneumoniae. Over time the bacterial loads increased in wild-type mice in blood, brain and lung. After $48 \mathrm{~h}, \mathrm{C} /$ $\mathrm{EBP}^{-/-}$mice had significant lower bacterial count in the blood as compared to wild-type (Fig. 1b). As shown in
Fig. 1c, C/EBP $\delta^{-1-}$ mice also presented lower bacterial counts in the brain as compared to wild-type mice $48 \mathrm{~h}$ after inoculation. Notably, the number of mice with bacteremic brains was increased in wild-type mice at $48 \mathrm{~h}$ $(14 / 29$ versus $5 / 28, \mathrm{p}=0.02$, odds ratio [OR] $4.2,95 \%$ confidence interval $[\mathrm{CI}] 1.13-18.1)$, whereas the number was similar in $\mathrm{C} / \mathrm{EBP}^{-1-}$ mice at $24 \mathrm{~h}(7 / 29$ versus $4 / 30$, $p=0.33$, OR 2.04, CI $0.45-10.83$ ). No difference was observed in bacterial counts in the lungs of wild-type and $\mathrm{C} / \mathrm{EBP}^{-1-}$ mice (Fig. 1d). Correlation analysis of cebpd mRNA expression and bacterial loads in the brain shows that C/EBP $\delta$ expression is positively and significantly correlated with the bacterial burden $(p=0.01$, 
Spearman $r=0.68$; Fig. 1e), suggesting that the increase in C/EBPS expression leads to bacterial dissemination.

\section{C/EBP $\delta$ does not affect the inflammatory response in brain during pneumococcal sepsis}

To determine whether $\mathrm{C} / \mathrm{EBP} \delta$ affects the inflammatory response in blood and brain during pneumococcal sepsis we measured different cytokine and chemokine levels in plasma and brain homogenates. As shown in Fig. 2, the host response as measured by cytokine and chemokine production in plasma was increased over time in both wild-type and $\mathrm{C} / \mathrm{EBP}^{-/-}$mice. IL-6 levels (Fig. 2a) were significantly lower at both 24 and $48 \mathrm{~h}$ post inoculation in $\mathrm{C} / \mathrm{EBP}^{-/-}$mice as compared to wild-type mice. IFN$\gamma$ (Fig. 2d) and MCP-1 (Fig. 2b) levels were significantly lower at 24 (IFN- $\gamma$ ) or 48 (MCP-1) hours post inoculation. No differences in TNF- $\alpha$ levels were observed between wild-type and $\mathrm{C} / \mathrm{EBP}^{-1-}$ mice (Fig. 2c). In brain, all measured cytokine and chemokine levels were very low (data not shown) and histological analysis of the brains did also not show clear signs of meningitis (data not shown).

\section{Discussion}

In the present study, we demonstrate that $\mathrm{C} / \mathrm{EBP} \delta$ plays a detrimental role during $S$. pneumoniae sepsis-induced meningitis. We show that $\mathrm{C} / \mathrm{EBP} \delta$ expression in the brain is induced after an intravenous challenge with $S$. pneumoniae, and that it aggravates bacterial dissemination from the blood to the brain thereby driving the progression towards meningitis. This notion is strengthened by the positive correlation between C/EBP $\delta$ gene expression levels and bacterial counts in the brain $48 \mathrm{~h}$ post challenge.

Several studies have implicated $\mathrm{C} / \mathrm{EBP} \delta$ as regulator of proinflammatory cytokine expression [29], which are in line with our finding that $24 \mathrm{~h}$ after inoculation, IL-6 and INF- $\gamma$ levels in plasma were significantly lower in the absence of $\mathrm{C} / \mathrm{EBP}$; and at $48 \mathrm{~h}$ post challenge, IL- 6 and MCP- 1 levels were lower in $\mathrm{C} / \mathrm{EBP}^{-/-}$mice. However, we were not able to detect differences in cytokine levels between groups in the brain compartment since pneumococcal sepsis only caused a very modest inflammatory response in the brain, as reflected by low inflammatory cytokine levels. In accordance with the inflammatory cytokine profile in brain, the absence of brain histopathological meningitis traits, even at $48 \mathrm{~h}$, indicates that the experimental model is merely suitable to study the initial process of the development of pneumococcal meningits. Because the mice eventually will start to clear the bacteria shortly after $48 \mathrm{~h}$ post inoculation, the sepsis model used is not suitable to study prolonged time points beyond $48 \mathrm{~h}$ which is a limitation of our study.
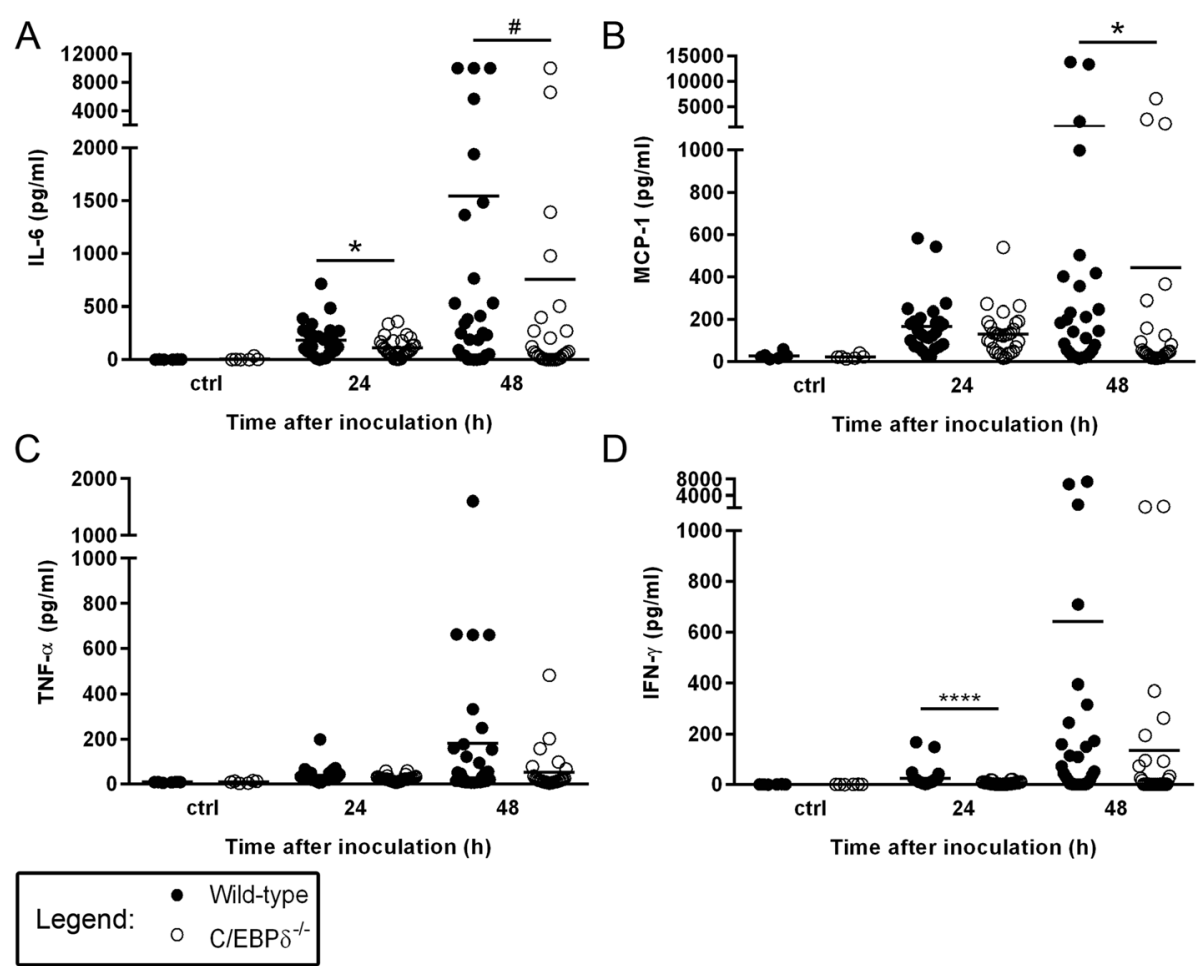

Fig. 2 C/EBPS affects the inflammatory response in plasma in pneumococcal blood-borne brain infection. Levels of IL-6 (a), MCP-1 (b), TNF-a (c) and IFN- $\gamma(\mathbf{d})$ in plasma of Wild-type and C/EBPS ${ }^{-1-}$ mice in S. pneumoniae blood-borne brain infection. Data are expressed as scatter dot plots with the median ( $n=6$ for controls; $n=30$ at both $\mathrm{t}=24$ and $\mathrm{t}=48 \mathrm{~h}$ post infection). $\# P=0.054,{ }^{*} P<0.05,{ }^{* * * *} P<0.0001$ 
In addition to the difference in bacterial loads in the brain we did not observe a difference in dissemination towards the lungs. This is in line with our previous study [21] in which we specifically studied the role of C/EBP $\delta$ in S. pneumoniae-induced pulmonary infection. In the previous study we did not observe a difference in bacterial loads in the blood of wildtype and $\mathrm{C} / \mathrm{EBP}^{-/-}$mice, which is in contrast with the current study where we did observe a difference in bacterial loads in the blood at $48 \mathrm{~h}$ post inoculation. The discrepancy between the two studies may be caused by the number of mice included. The number of mice included in the current study is approximately four times higher ( 8 versus 30 for the previous study and the current study respectively) which may have increased the power of the statistical analysis leading to a significant difference in the current study. More importantly however, the lack of a significant difference in dissemination towards the lungs suggests that the observed difference in bacterial loads in the brain between wildtype and $\mathrm{C} / \mathrm{EBP} \delta^{-1-}$ mice in the current study is not merely a reflection of the bacterial loads in the blood. Therefore we conclude that $\mathrm{C} / \mathrm{EBP} \delta$ plays a specific role in the dissemination of S. pneumoniae towards the brain.

Previously we have shown that upon intracisternal inoculation of pneumococci, C/EBP $\delta^{-1-}$ mice showed a decrease in bacterial outgrowth and inflammatory response in the brain as compared to wild-type mice [22]. Here we show that $\mathrm{C} / \mathrm{EBP}^{-/-}$mice have limited bacterial dissemination towards the brain upon intravenous inoculation of pneumococci. Taken together, these results show that $\mathrm{C} /$ EBP $\delta$ plays a dual and detrimental role during both the establishment and disease progression of pneumococcal meningitis. It can therefore be speculated that inhibition of C/EBP $\delta$ may reduce bacterial dissemination during both the establishment and subsequent progression of pneumococcal meningitis. However, further studies should elucidate the role of C/EBP $\delta$ as potential target for novel therapeutic interventions during meningitis.

\section{Conclusions}

Our results show that $\mathrm{C} / \mathrm{EBP} \delta$ expression in the brain increased in response to systemic $S$. pneumoniae infection, that $\mathrm{C} / \mathrm{EBP}^{-/-}$mice presented reduced bacterial dissemination to the brain and displayed a lower inflammatory response in plasma as measured by MCP-1 and IL-6. Overall, our results show that C/EBP $\delta$ plays a detrimental role during the initial development of meningitis caused by sepsis.

\section{Abbreviations}

C/EBP: CCAAT/enhancer binding protein; cDNA: complementary DNA;

CFU: Collony forming units; Cl: Confidence interval; CNS: Central nervous system; IFN: Interferon; IL: Interleukin; LPS: Lipopolysaccharide; MCP: Monocyte chemoattractant protein; MIP: Macrophage inflammatory protein;
NoNo: Non-POU-domain containing octamer binding protein; OR: Odds ratio; RT-PCR: Real-time polymerase chain reaction; S. pneumoniae: Streptococcus pneumoniae; TNF: Tumour-necrosis factor

\section{Acknowledgements}

The authors also like to thank Stefan R Havik and Joost Daalhuisen for their technical assistance during the animal experiments. The authors like to thank Bart Ferwerda for his statistical input.

\section{Funding}

This work was supported by grants from the European Research Council (ERC Starting Grant [proposal/contract 281156]), Netherlands Organization for Health Research and Development (ZonMw; NWO-Vidi grant 2010 [proposal/ contract 016.116.358]), both to DvdB.

\section{Availability of data and materials}

Data available on request from the authors. The data that support the findings of this study are available from the corresponding author upon reasonable request.

\section{Authors' contributions}

The work presented here was carried out in collaboration between all authors. Experimental procedures were carried out by JWD and MVS. Histological assessment of slides was performed by JYL. The manuscript was drafted by JWD and MVS and discussed and edited by MCB, DvdB and CAS. All authors have read and approved the final version of the manuscript.

\section{Competing interests}

The authors declare that they have no competing interests.

\section{Consent for publication}

Not applicable.

\section{Ethics approval and consent to participate}

All animal experiments were approved by the Institutional Animal Care and Use Committee of the Academic Medical Center, University of Amsterdam (protocol DIX102487)

\section{Author details}

${ }^{1}$ Center for Experimental and Molecular Medicine (CEMM) Academic Medical Center, University of Amsterdam, P.O. Box 22660, 1100DD Amsterdam, The Netherlands. ${ }^{2}$ Department of Neurology, Academic Medical Center, 1100DD Amsterdam, The Netherlands. ${ }^{3}$ Neuroinfection and Inflammation, Amsterdam Neuroscience, Amsterdam, The Netherlands.

Received: 27 August 2016 Accepted: 25 October 2016

Published online: 11 November 2016

\section{References}

1. van der Poll T, Opal SM. Pathogenesis, treatment, and prevention of pneumococcal pneumonia. Lancet (London, England). 2009;374(9700):1543-56.

2. Henriques-Normark B, Tuomanen El. The pneumococcus: epidemiology, microbiology, and pathogenesis. Cold Spring Harbor Perspectives Medicine. 2013;3:7.

3. Mook-Kanamori BB, Geldhoff M, van der Poll T, van de Beek D. Pathogenesis and pathophysiology of pneumococcal meningitis. Clin Microbiol Rev. 2011:24(3):557-91.

4. Brouwer MC, Tunkel AR, van de Beek D. Epidemiology, diagnosis, and antimicrobial treatment of acute bacterial meningitis. Clin Microbiol Rev. 2010;23(3):467-92

5. Bijlsma MW, Brouwer MC, Kasanmoentalib ES, Kloek AT, Lucas MJ, Tanck MW van der Ende A, van de Beek D. Community-acquired bacterial meningitis in adults in the Netherlands, 2006-14: a prospective cohort study. Lancet Infect Dis. 2016:16(3):339-47.

6. van de Beek D, de Gans J, Spanjaard L, Weisfelt M, Reitsma JB, Vermeulen M. Clinical features and prognostic factors in adults with bacterial meningitis. N Engl J Med. 2004;351(18):1849-59.

7. van de Beek D, Brouwer MC, Thwaites GE, Tunkel AR. Advances in treatment of bacterial meningitis. Lancet (London, England). 2012;380(9854):1693-702. 
8. Mclntyre PB, O'Brien $\mathrm{KL}$, Greenwood B, van de Beek D. Effect of vaccines on bacterial meningitis worldwide. Lancet (London, England). 2012;380(9854): 1703-11.

9. Weisfelt M, de Gans J, van der Poll T, van de Beek D. Pneumococcal meningitis in adults: new approaches to management and prevention. Lancet Neurol. 2006;5(4):332-42.

10. van de Beek D, Schmand B, de Gans J, Weisfelt M, Vaessen H, Dankert J, Vermeulen M. Cognitive impairment in adults with good recovery after bacterial meningitis. J Infect Dis. 2002;186(7):1047-52.

11. Schut ES, Lucas MJ, Brouwer MC, Vergouwen MD, van der Ende A, van de Beek D. Cerebral infarction in adults with bacterial meningitis. Neurocrit Care. 2012;16(3):421-7.

12. Zoons E, Weisfelt M, de Gans J, Spanjaard L, Koelman JH, Reitsma JB, van de Beek D. Seizures in adults with bacterial meningitis. Neurology. 2008:70(22 Pt 2):2109-15.

13. Hoogman M, van de Beek D, Weisfelt M, de Gans J, Schmand B. Cognitive outcome in adults after bacterial meningitis. J Neurol Neurosurg Psychiatry. 2007;78(10):1092-6.

14. van de Beek D, de Gans J, Tunkel AR, Wijdicks EF. Community-acquired bacterial meningitis in adults. N Engl J Med. 2006;354(1):44-53.

15. Lucas MJ, Brouwer MC, van de Beek D. Neurological sequelae of bacterial meningitis. J Infect. 2016;73(1):18-27.

16. Lekstrom-Himes J, Xanthopoulos KG. Biological role of the CCAAT/ enhancer-binding protein family of transcription factors. J Biol Chem. 1998: 273(44):28545-8.

17. Ramji DP, Foka P. CCAAT/enhancer-binding proteins: structure, function and regulation. Biochem J. 2002;365(Pt 3):561-75

18. Yan C, Zhu M, Staiger J, Johnson PF, Gao H. C5a-regulated CCAAT/ enhancer-binding proteins beta and delta are essential in Fcgamma receptor-mediated inflammatory cytokine and chemokine production in macrophages. J Biol Chem. 2012;287(5):3217-30.

19. Maitra U, Gan L, Chang S, Li L. Low-dose endotoxin induces inflammation by selectively removing nuclear receptors and activating CCAAT/enhancerbinding protein delta. J Immunol. 2011;186(7):4467-73.

20. Litvak V, Ramsey SA, Rust AG, Zak DE, Kennedy KA, Lampano AE, Nykter M, Shmulevich I, Aderem A. Function of C/EBPdelta in a regulatory circuit that discriminates between transient and persistent TLR4-induced signals. Nat Immunol. 2009;10(4):437-43.

21. Duitman J, Schouten M, Groot AP, Borensztajn KS, Daalhuisen JB, Florquin S, van der Poll T, Spek CA. CCAAT/enhancer-binding protein delta facilitates bacterial dissemination during pneumococcal pneumonia in a plateletactivating factor receptor-dependent manner. Proc Natl Acad Sci U S A. 2012;109(23):9113-8.

22. Valls Seron M, Duitman J, Geldhoff M, Engelen-Lee J, Havik SR, Brouwer MC, van de Beek D, Spek CA. CCAAT/enhancer-binding protein delta (C) EBPdelta) aggravates inflammation and bacterial dissemination during pneumococcal meningitis. J Neuroinflammation. 2015;12:88.

23. Chiavolini D, Pozzi G, Ricci S. Animal models of streptococcus pneumoniae disease. Clin Microbiol Rev. 2008;21(4):666-85.

24. Sterneck E, Paylor R, Jackson-Lewis V, Libbey M, Przedborski S, Tessarollo L, Crawley JN, Johnson PF. Selectively enhanced contextual fear conditioning in mice lacking the transcriptional regulator CCAAT/enhancer binding protein delta. Proc Natl Acad Sci U S A. 1998;95(18):10908-13.

25. van der Windt GJ, Hoogendijk AJ, Schouten M, Hommes TJ, de Vos AF, Florquin S, van der Poll T. Osteopontin impairs host defense during pneumococcal pneumonia. J Infect Dis. 2011;203(12):1850-8.

26. van der Windt GJ, Blok DC, Hoogerwerf JJ, Lammers AJ, de Vos AF, Van't Veer C, Florquin S, Kobayashi KS, Flavell RA, van der Poll T. Interleukin 1 receptor-associated kinase $\mathrm{m}$ impairs host defense during pneumococcal pneumonia. J Infect Dis. 2012;205(12):1849-57.

27. Mook-Kanamori B, Geldhoff M, Troost D, van der Poll T, van de Beek D. Characterization of a pneumococcal meningitis mouse model, BMC Infect Dis. 2012;12:71.

28. R DCT. R: A Language and Environment for Statistical Computing. Vienna: Austria R Foundation for Statistical Computing; 2008.

29. Balamurugan $\mathrm{K}$, Sterneck $\mathrm{E}$. The many faces of C/EBPdelta and their relevance for inflammation and cancer. Int J Biol Sci. 2013;9(9):917-33.

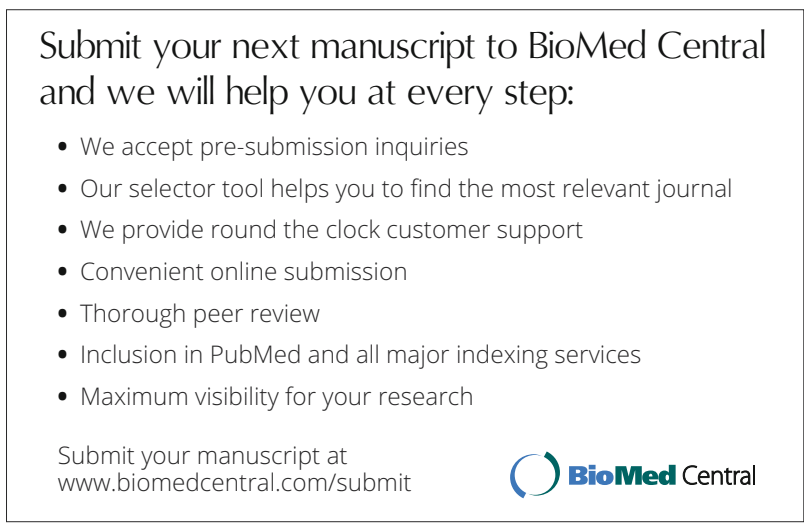

